Journal of Teacher Education for Sustainability, vol. 19, no. 1, pp. 43-53, 2017

\title{
Secondary School Science Teachers' Views about Their Reflective Practices
}

\author{
Abdulwali H. Aldahmash, Saeed M. Alshmrani, and Abdo N. Almufti \\ Excellence Research Centre for Science and Mathematics Education, \\ King Saud University, Saudi Arabia
}

\begin{abstract}
The importance of reflection in teaching and learning lies in encouraging one to view problems from different perspectives. Reflective practice can be useful in designing teacher education and sustainable professional development. Conscious reflection is an important element for helping teachers and learners in problem-solving and decision-making processes and fostering their critical-thinking abilities. The aim of the present research was to investigate teachers' views about the nature of their experiences with reflective practices and reflective teaching. A survey consisted of three dimensions used to collect the data. It was distributed to 458 ( 237 male and 221 female) science teachers working at high schools in Saudi Arabia. The results have indicated that teacher practices of almost all reflective activities included in the three dimensions "the extent of practicing reflection", "areas of practicing reflection", and "ways of practicing reflection" are at "high" level from their point of view. The results have also shown that there are no significant differences in the teachers' views about their practices of reflective activities related to their gender, or experiences in the teaching profession.
\end{abstract}

Keywords: reflection, reflective practice, consciousness, sustainable professional development.

\section{Introduction}

For educational improvement, teacher professionalism is essential. There is much interplay between primary and reflective consciousness that can foster teacher sustainable professional development (Reid \& Horváthová, 2016). Yoo (2016) has argued that to ensure sustainable development, educators should focus on studies related to teacher programmes. In addition, Back et al. (2009) stress that the development of reflection on practice is essential for sustainable professional development. One of the important natural phenomena that has a notable effect on sustainable professional development is conscious reflection. The relation between reflection and consciousness is simple, if teachers reflect critically on their work or PD providers reflect carefully on the programs, then they can make conscious choices about their experience, which in turn may enable them to strengthen the quality and effectiveness of their work (Reagan, 1993; Adeyemi, 
1996). In this regard, McIyntre (1993: p. 43), McIyntre (1993: p. 43) state that teachers' experience turns to be "automated or intuitive, dependent on understandings that are not usually articulated, that learning for them is dependent on bringing to consciousness and examining the assumptions and considerations which make sense of their actions as teachers". Zahvi (2006) characterises reflection as higher-order monitoring and defines it as "the process whereby consciousness directs its intentional aim at itself, thereby taking itself as its own object". Osterman and Kottkamp (2004), in their turn, describe reflection as a professional development strategy that can equip professionals with "opportunities to explore, articulate and represent their own ideas and knowledge". Therefore, McAlpine and Weston (2000) argue that reflection is helpful in fostering professional growth. On the other hand, Dewey asserts that the purpose of reflective practice is to direct the teacher in taking actions and making decisions. He adds that reflection is a holistic orientation to teaching that can be helped to acquire, rather than a procedure that can be taught (Zeichner \& Liston, 1996).

In general terms, reflection is considered to be "an important human activity in which people recapture their experience, think about it, mull over \& evaluate it" (Boud, Keogh, \& Walker, 1985, p. 19). It is considered as intellectual and affective abilities in which individuals engage to explore their experiences in order to achieve new understandings and appreciations. On the other hand, Loughran, (1996: p. 4) considers reflection as a process that may be applied in puzzling situations to help the learner make better sense of the information at hand and to enable the teacher to guide and direct learning in appropriate ways.

Jerez $(2008$, p. 91) asserted that PD programs use reflection to develop teaching, Tate \& Sills (2004, p. 126) also stress the role of reflection on learning by saying "We learn through critical reflection by putting ourselves into the experience $\&$ exploring personal \& theoretical knowledge to understand it \& view it in different ways". Teachers generally reflect on their teaching and students' learning in order to improve their practice and cognitive awareness of their reflective processes (Tomlinson, 1999a; 1999b; McAlpine, Weston, Berthiaume, \& Fairbank, 2004).

Revonsuo (2006, p. 10) indicates that biological realism deals with consciousness as a "real natural biological phenomenon". He describes self-conscious reflection as the highest level of operation of a human brain. In addition, Zahavi (2004d, p. 14) states, "Consciousness is inherently temporal, and it is as temporal that it is pre-reflectively aware of itself".

Conscious reflective practice can be useful in designing sustainable teacher education (Raid \& Horvathova, 20016; and Soobik, 2014) and sustainable professional development (Sarsar, 2008). Donald Schön considers it to be an important factor for helping teachers and learners in problem-solving and decision-making processes and fostering their critical-thinking abilities. He notes that this can be done through the process of the reflective conversation approach. In this regard, he states, "The reflective practitioner re-frames problems to create a reflective conversation in which practice 'talks back'. In this reflective conversation, the practitioner's effort to solve the reframed problems yields new discoveries, which call for new reflection-in-action. The process spirals through stage appreciation, action, and re-appreciation. The unique and uncertain situation comes to be understood through the attempt to change it, and changed through the attempt to understand it" (Schön, 1983, p. 132). Similarly, Griffiths \& Tann (1991, p. 100) state, "reflective teaching requires that public theories are translated into personal 
ones and vice versa unless teachers are going to allow themselves to be turned into lowlevel operatives, content with carrying out their tasks more and more efficiently, while remaining blind to large issues of the underlying purposes and results of schooling”.

Regarding the meaning of reflective practice concept in teaching, this concept has been introduced as thinking critically about what is happening in the classroom where the teacher teaches (Campoy, 2010). This can be done through critical observation of his/her practices in the classroom and their critical evaluation by gathering information, then it is possible to manipulate practices and use them to modify his/her behaviour. Richards (1990) describes reflective teaching as a transfer from the ordinary to higherlevel awareness of teaching practice. Pollard and Tann (1989) describe reflective teaching as a systematic process of investigating teachers' own practice. Hubball, Collins and Pratt $(2005$, p. 60) define reflective practice as "the thoughtful consideration and questioning of what we do, what works and what doesn't, and what premises and rationales underlie our teaching and that of others". Generally, Dewey defines reflective practice as an "active, persistent, and careful consideration of any belief or supposed form of knowledge in the light of the grounds that support it and the further conclusions to which it tends..." (1933, p. 6). From Dewey's point of view, reflective teachers depend on reasoned principles while teaching rather than acting routinely and following instructions without questioning. They critically think about their own teaching practice and try to solve problems, which might be related to their educational and social contexts.

The dominant theme for reflective practice is the theory-practice interrelation. Day (2001) indicates that theories can be used to reflect on practice and then reflection may lead the participant to critique his or others practice. He states, "Without routinely engaging in reflective practice, it is unlikely that we will be able to understand the effects of our motivations, prejudices, and aspirations upon the ways in which we create, manage, receive, sift, and, evaluate knowledge" (Day, 1999b, p. 229). On the other hand, Cimer, Cimer, \& Vekli (2013), Craig (1994) argue that teacher's awareness of the term "reflective practice" and the importance of being reflective may not really apply to their real-life teaching experience and stress that knowledge may not lead to action because teaching theories do not control classroom actions.

Concerning the benefits of conscious reflection and hence conscious reflective practice, we are convinced that reflection on teaching practice is important for educators and teachers all over the world. It helps Professional Development Programmes (PDP) providers make teachers' professional development programmes more effective and sustainable (Ried \& Hrvathova, 2016; Pipere, Veisson, \& Salite, 2015; Jerez, 2008). Reflection on teaching is also important in fostering students' learning (Tate \& Sills, 2004, p. 126). Therefore, reflecting in practice enables teachers to challenge teaching practices and then to perform well in lesson design, curriculum decision-making, class management, and execution of teaching activities. Reflection in action may also help teachers deal with the school and other teaching contexts where it is difficult to find time away from the students to reflect with colleagues. In addition, Moon (1999) further identifies the ways in which reflection plays an important role in learning:

- Reflection slows down activity: the learner has time to process the material, linking it to previous ideas;

- Reflection gives learners a sense of ownership of taught material, making it more personally meaningful; 
- Reflection encourages metacognition, the awareness of one's own cognitive processes; and

- Reflection encourages students to challenge their learning, resulting in a greater commitment.

\section{Aim of the Study}

The motive behind the study is to shed light on the role of conscious reflective practice on Saudi teachers' professionalism and their sustainable professional development. The research tries to unveil whether the Saudi science teachers are aware of reflective practices and whether they apply them or not. The paper also attempts to show what strategies the participants use to reflect. In addition, we have discussed the effect of gender, experience, and type of educational background variables on teachers' reflective practices. More specifically, the research tries to find answers to the following questions:

- To what extent do the teachers involve reflection in the classroom while teaching?

- How do teachers consciously reflect on their practice?

- What strategies do teachers use to reflect on their practice?

- Do gender, the length of experience, and level of education make a significant difference in teachers' conscious reflection?

\section{Methodology}

A descriptive method was used for this study. Hence, the study followed the survey research design to generate relevant data in the study about the nature of secondary school teachers' experiences and implementation or practice of conscious reflective practice activities in their professional life.

\section{Participants}

The sample of the study involved 458 secondary school science teachers (237 male and 221 female) working at high schools located in the governorates of Hhael and Hafer-Albaten in Saudi Arabia. The participants' experience in teaching ranges between 1 to 30 years of experience in science teaching. These experiences are categorised into three types: those who served less than 5 years (145), those who had 5 to 10 years of experience (121) and, finally, those who had more than 10 years of experience (146). Regarding their academic level, 388 of the participants are holders of BA degrees and the other 42 just have the diploma, (5) of the teachers have the MA degree, and 32 of them hold PhD.

Regarding the type of certificate, it was found that 411 of the participants have an educational background and hold a certificate, while 44 do not have any educational background or educational certificate. The domains of specialisation of the participants are physics (65), chemistry (71), and biology (84). 


\section{The Questionnaire}

In this study, the survey research design has been used to investigate the nature of secondary school teachers' experiences and implementation of reflective practice in their professional life. Therefore, a questionnaire has been adopted from Celes, (2010), and modified in accordance with the aims of the study in order to collect data. The questionnaire consists of three parts. The first part includes the instruction to the participants in addition to three questions about gender, experience, type of certificate, and the level of education. The second part of the questionnaire shows a list of 20 reflection practices for the participants to select how frequently they practice each item (never, rarely, sometimes, often, or usually). The questionnaire has been found to be reliable. The SPSS has been used to find the reliability coefficient of the questionnaire (Alpha $=0.8602$ ).

\section{Internal Consistency}

Pearson correlation coefficient (Pearson Correlation) of collected data has been used to identify the consistency of each item with the dimension (see Table1). The table shows that all items are related to their domains with a statistical level significance of $(\alpha \leq 0.01)$, with high and medium values, as the correlation coefficient in all paragraphs is 0.407 and 0.792. Carpenter and Hanafi (2013) indicated that the value is medium if between (0.3) and (0.7), and high if higher than (0.7).

Table 1

Persons' Correlation Coefficients for the Survey Items with Their Domains

\begin{tabular}{ccccccc}
\hline Domain & Item & Correlation & Item & Correlation & Item & Correlation \\
\hline Extent of practicing reflection & 1 & $0.614^{* *}$ & 4 & $0.674^{* *}$ & 7 & $0.680^{* *}$ \\
\cline { 2 - 7 } & 2 & $0.689^{* *}$ & 5 & $0.683^{* *}$ & & \\
\cline { 2 - 7 } & 3 & $0.719^{* *}$ & 6 & $0.711^{* *}$ & & \\
\hline Areas of practicing reflection & 1 & $0.711^{* *}$ & 3 & $0.703^{* *}$ & 5 & $0.744^{* *}$ \\
\cline { 2 - 7 } & 2 & $0.674^{* *}$ & 4 & $0.785^{* *}$ & & \\
\hline Ways of practicing reflection & 1 & $0.407^{* *}$ & 4 & $0.792^{* *}$ & 7 & $0.716^{* *}$ \\
\cline { 2 - 7 } & 2 & $0.554^{* *}$ & 5 & $0.765^{* *}$ & 8 & $0.740^{* *}$ \\
\cline { 2 - 7 } & 3 & $0.711^{* *}$ & 6 & $0.789^{* *}$ & & \\
\hline
\end{tabular}

Significant at $(\alpha=0.01)$

\section{Reliability}

To calculate the reliability of the survey, Cronbach Alpha coefficient (Cronbach's Alpha) has been calculated. The Cronbach Alpha values for the first domain "Extent of practicing reflection" were 0.811 . For the second domain "Areas of practicing reflection" values accounted for 0.771 , and for the third domain "Ways of practicing reflection" 0.844. The Cronbach Alpha value for the whole survey was 0.898 , these values give a positive indication towards using the tool, and the reliability of the data collected. 


\section{Results}

A survey with a five-point Likert scale (very high, high, medium, low, and very low) has been prepared and distributed to the sample. The study tool response ranges between lower level "very low", as represented numerically by (1), and higher level "very high", which is represented numerically by (5). To help interpreting the results, the responsiveness of the sample to each item has been set according to the following standards: very low (1 to 1.80 ), low (> 1.80 to 2.60 ), medium (> 2.60 to 3.40 ), high (>3.40 to 4.20$)$, and very high (> 4.20 to 5.0$)$.

Table 2

Descriptive Statistics for the First Dimension of the Reflective Activities' Instrument "The Extent of Practicing Reflection"

\begin{tabular}{llccc}
\hline$\#$ & \multicolumn{1}{c}{ Item } & Mean & SD & Level of practice \\
\hline 1 & Practicing reflection during writing the lesson & 3.92 & 0.773 & High \\
\hline 2 & Practicing reflection while doing the lesson & 3.75 & 0.802 & High \\
\hline 3 & Practicing reflection at the end of the lesson & 3.71 & 0.866 & High \\
\hline $\begin{array}{l}4 \\
\begin{array}{l}\text { Practicing reflection after the completion of teaching } \\
\text { a unit or a chapter of the book }\end{array}\end{array}$ & 3.64 & 0.869 & High \\
\hline 5 & $\begin{array}{l}\text { Practicing reflection after a visit by the supervisor or } \\
\text { the principal }\end{array}$ & 3.84 & 0.843 & High \\
\hline 6 & Practicing reflection after a meeting with parents & 3.62 & 0.930 & High \\
\hline 7 & Practicing reflection after finishing a training session & 4.05 & 0.866 & High \\
\hline Total & 3.79 & 0.580 & High \\
\hline
\end{tabular}

The results in Table 2 show that the means of sample responses to the items related to the domain "The extent of practicing reflection" range between 3.62 and 4.05, which indicates that all are located at the level of practice "high". The highest item in this domain exercised by teachers is "Practicing reflection after finishing a training session" with an arithmetic mean of 4.05 , and a standard deviation of 0.088 , while the least exercised item is "Practicing reflection after a meeting with parents" with an arithmetic mean of 3.62, and a standard deviation of 0.930 .

Table 3

Descriptive Statistics for the Second Dimension of the Reflective Activities' Instrument "Areas of Practicing Reflection"

\begin{tabular}{llccc}
\hline$\# \quad$ Item & Mean & SD & Level of practice \\
\hline 1 & Lesson planning & 3.99 & 0.741 & High \\
\hline 2 & $\begin{array}{l}\text { Selection of teaching method or activities suitable for } \\
\text { the subject to be taught }\end{array}$ & 4.03 & 0.783 & High \\
\hline 3 & Class management & 4.04 & 0.878 & High \\
\hline $4 \quad$ Selection of evaluation and assessment strategies & 3.88 & 0.866 & High \\
\hline $\begin{array}{l}\text { Preparation and implementation of procedural or } \\
\text { action research aimed to detect and fix errors in the } \\
\text { teaching process }\end{array}$ & 3.68 & 0.898 & High \\
\hline \begin{tabular}{l} 
Total \\
\hline
\end{tabular} & 3.93 & 0.603 & High \\
\hline
\end{tabular}


The data in Table 3 show that the mean of respondents' responses on the second dimension "Areas of practicing reflection" ranges from 3.68 to 4.04. This indicates that all items of this dimension gained a higher level of practice from teachers' point of view. Teachers highly feel they are practicing meditation when planning a lesson while choosing teaching methods, classroom management, and in the selection of methods and procedures for the assessment, and when preparing research. The area that gained the highest level of practice as seen by teachers is classroom management with an arithmetic mean of 4.04 and standard deviation of 0.878 . The least practice area is preparing and implementing procedural or action research designed to detect and repair errors in the teaching process with an arithmetic mean of 3.68 and a standard deviation of 0.898 . The results show that all teachers' answers to items fell into the high-ranking level of practice.

Table 4

Descriptive Statistics for the Third Dimension of the Reflective Activities' Instrument "Ways of Practicing Reflection"

\begin{tabular}{llccc}
\hline$\#$ & \multicolumn{1}{c}{ Item } & Mean & SD & Level of practice \\
\hline 1 & Mind reflection alone & 3.97 & 0.789 & High \\
\hline 2 & Reflecting in writing alone & 3.65 & 0.884 & High \\
\hline 3 & Mind reflection with another person within the school & 3.54 & 0.902 & High \\
\hline 4 & Mind reflection with another person outside the school & 3.41 & 0.991 & High \\
\hline 5 & $\begin{array}{l}\text { Reflection in writing with another person within the } \\
\text { school }\end{array}$ & 3.29 & 1.11 & Medium \\
\hline 6 & $\begin{array}{l}\text { Reflection in writing with another person outside the } \\
\text { school }\end{array}$ & 3.19 & 1.10 & Medium \\
\hline $7 \begin{array}{l}\text { Mind reflection in writing with a group of teachers } \\
\text { within the school }\end{array}$ & 3.74 & 0.956 & High \\
\hline 8 & $\begin{array}{l}\text { Mind reflection in writing with a group of teachers } \\
\text { outside the school }\end{array}$ & 3.44 & 1.09 & High \\
\hline Total & 3.53 & 0.680 & High \\
\hline
\end{tabular}

According to Table 4, the means for respondents' response to "Ways of practicing reflection" range between 3.19 and 3.97. All of these values are located in the high level of practice, except two: item 4 "Mind reflection with another person outside the school" and item 5 "Reflection in writing with another person within the school". They gained a medium level of practice according to the teachers' views. The results show that six of the teachers' answers to items fall into the high-ranking level of practice, while two of the answers to items "Reflection in writing with another person within the school", and "Reflection in writing with another person outside the school" fell into "medium" ranking level of practice. 
Abdulwali H. Aldahmash, Saeed M. Alshmrani, and Abdo N. Almufti

Table 5

ANOVA Test of the Differences between Teachers according to Their Experience with Reflective Activities

\begin{tabular}{lcccccccccc}
\hline \multirow{2}{*}{ Domain } & \multicolumn{2}{c}{$\begin{array}{c}<5 \text { years } \\
(\mathrm{N}=145)\end{array}$} & \multicolumn{2}{c}{$\begin{array}{c}5 \text { to } 10 \text { years } \\
(\mathrm{N}=121)\end{array}$} & \multicolumn{2}{c}{$\begin{array}{c}>10 \\
(\mathrm{~N}=146)\end{array}$} & F & df & sig \\
\cline { 2 - 7 } & Mean & SD & Mean & SD & Mean & SD & & & \\
\hline $\begin{array}{l}\text { Extent of practicing } \\
\text { reflection }\end{array}$ & 3.806 & 0.604 & 3.693 & 0.576 & 3.785 & 0.577 & 1.353 & 409 & 0.260 \\
\hline $\begin{array}{l}\text { Areas of practicing } \\
\text { reflection }\end{array}$ & 3.885 & 0.673 & 3.909 & 0.586 & 3.926 & 0.568 & 0.169 & 409 & 0.845 \\
$\begin{array}{l}\text { Ways of practicing } \\
\text { reflection }\end{array}$ & 3.491 & 0.703 & 3.598 & 0.627 & 3.455 & 0.705 & 1.542 & 409 & 0.215 \\
\hline
\end{tabular}

Table 5 shows that there are no significant differences among teachers in all three areas of reflection according to their experience in teaching profession.

Table 6

t-Test of the Differences in Reflective Activities between Teachers according to Their Gender

\begin{tabular}{lcccccccc}
\hline \multirow{2}{*}{ Domain } & \multicolumn{2}{c}{ Male $(\mathrm{N}=237)$} & \multicolumn{2}{c}{ Female $(\mathrm{N}=221)$} & \multirow{2}{*}{$\mathrm{t}$} & \multirow{2}{*}{ df } \\
\cline { 2 - 7 } & Mean & SD & Mean & SD & & & \\
\hline Extent of practicing reflection & 3.7864 & 0.575 & 3.7975 & 0.586 & 0.203 & 456 & 0.839 \\
\hline Areas of practicing reflection & 3.9179 & 0.589 & 3.9328 & 0.620 & 0.263 & 456 & 0.792 \\
\hline Ways of practicing reflection & 3.5163 & 0.719 & 3.5454 & 0.637 & 0.457 & 456 & 0.648 \\
\hline
\end{tabular}

Similarly, Table 6 shows that there are no significant differences among teachers in all three areas of reflection with regard to their gender.

\section{Discussion}

This research has shed light on the nature of science teachers' reflective practice in high schools in Saudi Arabia. It is obvious that gender, experience, and education do not play a role in teachers' reflection. However, teachers' awareness of the importance of reflection in their professional growth does not necessarily mean that teachers apply conscious reflection in their teaching experience. Teachers have been found to make decisions based on context evaluation while teaching. However, the participants do not follow up by reflecting on their actions and assess the effectiveness of the decision they made in the classroom.

The present study indicates that nearly all teachers included in the study indicate that they highly practice reflection in their profession. Several similar studies (Ried \& Hrvathova, 2016; McAlpine \& Weston, 2000; Osterman \& Kottkamp, 2004; Hung, 2008; Heng \& Khim, 2004) suggest that conscious reflection fosters professional growth. This indicates that teacher preparation institutes give enough importance to reflective skills to be used in their future profession. The second area of reflection "areas of practicing reflection" is similar to reflection-in-action as described by Schön (1987). He suggested that this type refers to the importance of teachers' awareness of their decisions while they work and in their ability to take the necessary actions towards the following actions. 
There is no doubt that conscious reflection is essential for sustainable professional growth (Ried \& Hrvathova, 2016) and more effective teaching. The teachers indicate that they practice almost most reflection types included in the area "ways of practicing reflection" when they reflect alone, but the level of their reflection is found to be medium when they reflect with other teachers within the school or outside the school (Table 4). This may indicate that teachers do not practice reflection in groups, whether inside or outside the schools. This is because they are not involved in any type of community of practice as was indicated in our previous study (Aldahmash, 2016). Teachers' ways of practicing reflection are similar to reflection-on-action that is type of reflection described by Schön (1987). He indicates that reflection-on-action engages the teacher with many processes, which enhance professional growth such as reviewing, analysing and evaluating the situation. The present research shows that a majority of teachers are highly aware of the contexts where they teach and that they practice both levels of reflections.

In order to help teachers become more reflective, it is recommended that teacher professional development programmes include materials that help teachers acquire reflective abilities (Kabadayi, 2016; Ferraro, 2000). It is also recommended that providers should also include reflective practice in their CPD programmes. Teacher's supervisor should ask the teacher to write a reflective journal by the end of every academic year.

Despite the fact that teachers have indicated that they are practicing reflection, it is not clear whether they are aware of the term "reflection" or not. Therefore, it is important to conduct a research study on teachers' perspectives or understanding of conscious reflection. It is also important to conduct a research study to investigate if the teacher really practices conscious reflection in the real classroom. In this regard, Cimer, Cimer, \& Vekli (2013); Craig (1994) argue that teachers may have knowledge of the term "reflective practice" and the importance of being consciously reflective, but they may not really apply it to their real-life teaching experience, and hence most knowledge does not directly lead to action.

\section{References}

Adeyemi, M. B. (1996). The relative effectiveness of the reflective and lecture approach methods on the achievement of high school social studies students. Educational Studies, 18(1), 49-56.

Aldahmash, A. H. (2016). Saudi Arabian science teachers' trends in science teaching practices of teaching related scientific activities according to their supervisor's perspective and the supervisor's estimates of the importance of such practices. Journal of Educational and Psychological Studies - Sultan Qaboos University, 10(3), 577-595.

Back, J., De Geest, E., Hirst, C., \& Joubert, M. (2009). Final Report: Researching Effective CPD in Mathematics Education (RECME). Sheffield: NCETM.

Bakutyte, R., \& Ušeckienè, L. (2010). In-service training of pre-school pedagogues as a way towards sustainable development. Discourse and Communication for Sustainable Education, 1, 58-65.

Boud, D., Keogh, R., \& Walker, D. (1985). Promoting reflection in learning: A model. In D. Boud, R. Keogh, \& D. Walker (Eds.), Reflection: Turning the Experience into Learning (pp. 18-40). London: Kogan. 
Campoy, R. (2010). Reflective thinking and educational solutions: Clarifying what teacher educators are attempting to accomplish. Journal of the Southern Regional Association of Teacher Educators, 19(2), 15-22.

Celes, R. R. (2010). Reflective Practice: The Teacher in the Mirror. Unpublished doctoral thesis, Graduate College, University of Nevada, Las Vegas.

Cimer, A., Cimer, S. O., \& Vekli, G. S. (2013). How does reflection help teachers to become effective teachers? International J. Educational Research, 1(4). ISSN: 2306-7063.

Craig, R. (1994). Reflection and imagination: A holistic approach to teacher education. Teacher Education Quarterly, 21(3).

Day, C. (2001). Professional development and reflective practice: Purposes, processes, and partnerships. The Course named "Understanding and Developing Reflective Practice" readings. School of Education, University of Nottingham, Nottingham.

Dewey, J. (1933). How we think: A restatement of the relation of reflective thinking to the educative process. Chicago: Henry Regnery.

Ferraro, J. M. (2000). Reflective practice and professional development. ERIC Digest, No: ED449120.

Gay, G., \& Kirkland, K. (2003). Developing cultural critical consciousness and selfreflection in pre-service teacher education. Theory into Practice, 42(3), 181-187.

Heng, L. W., \& Khim, T. S. (2004). Reflective Practice in Malaysian Teacher Education: Assumptions, Practices, and Challenges. Singapore: Marshall Cavendish Academic.

Hubball, H., Collins, J., \& Pratt, D. (2005). Enhancing reflective teaching practices: Implications for faculty developmental programs. Canadian Journal of Higher Education, 35(3), 57-81. Retrieved 9 February 2009, from EBSCO Online Database http://search.ebscohost.com/login.aspx?direct=true $\% 2 \mathrm{bdb}=\mathrm{ehh} \% 2 \mathrm{bAN}=$ $20815234 \% 2$ bsite=ehost-live.

Hung, H. (2008). Teacher learning: Reflective practice as a site of engagement for professional identity construction. US- China Education Review, 5(5), 39-49.

Jerez R. S. (2008). Teachers' Attitudes towards Reflective Teaching: Evidence in a Professional Development Program (PDP). Profile Issues in Teachers' Professional Development, (10), 91-112. Retrieved 18 January 2017, from http://www.scielo.org.co/ scielo.php?script=sci_arttext\&pid=S1657-07902008000200006\&lng=en\&tlng=en

Kabadayi, A. (2016). A suggested in-service training model based on Turkish preschool teachers' conceptions for sustainable development. Journal of Teacher Education for Sustainability, 18(1), 5-15.

McAlpine, L., Weston, C., Berthiaume, D., \& Fairbank-Roch, G. (2004). Reflection on teaching: Types and goals of reflection. Educational Research and Evaluation, 10(46), 337-363. Retrieved 9 February 2009, from EBSCO Online Database Education Research. http://search.ebscohost.com/login.aspx?direct=true $\% 2 \mathrm{bdb}=\mathrm{ehh} \% 2 \mathrm{bAN}=$ $20815234 \% 2$ bsite=ehost-live

McAlpine, L., \& Weston, C. (2000). Reflection: Issues related to improving professors' teaching and students' learning. Instructional Science, 28(5/6), 363-385. Retrieved 9 February 2009, from EBSCO Online Database Education Research http://search. ebscohost.com/login.aspx? direct=true $\% 2 \mathrm{bdb}=\mathrm{ehh} \% 2 \mathrm{bAN}=20815234 \% 2 \mathrm{bsite}=$ ehost-live

McIyntre, D. (1993). Theory, theorising, and reflection in pre-service teacher education. In J. Calderhead \& P. Gates (eds.), Conceptualising Reflection in Teacher Development (pp. 39-52). London: the Falmer Press. 
Moon, J. A. (1999). Reflection in learning and professional development: Theory and practice. London: Kogan Page.

Pipere, A., Veisson, M., \& Salite, I. (2015). Developing research in teacher education for sustainability: UN DESD via the journal of teacher education for sustainability. Journal of Teacher Education for Sustainability, 17(2), 5-43.

Reagan, T. (1993). Educating the 'reflective practitioner': The contribution of philosophy of education. Journal of Research and Development in Education, 26(4), 189-196.

Reid E., \& Horváthová, B. (2016).Teacher training programs for gifted education with focus on sustainability. Journal of Teacher Education for Sustainability, 18(2), 12-30.

Revonsuo, A. (2006). Inner presence. Consciousness as a Biological Phenomenon. Cambridge, MA: MIT Press.

Ried, E., \& Hrvathova, B. (2016). Teacher training programs for gifted education with focus on sustainability. Journal of Teacher Education for Sustainability, 18(2), 66-74.

Sarsar, M. N. (2008). Adopting a Reflective Approach to Professional Development. Retrieved 9 February 2009, from EBSCO Online Database Education Research. http://search.ebscohost.com/login.aspx?direct=true $\% 2 \mathrm{bdb}=\mathrm{ehh} \% 2 \mathrm{bAN}=$ $20815234 \% 2$ bsite=ehost-live

Schön, D. A. (1983). The Reflective practitioner: How professionals think in action. New York: Basic Books. (Reprinted in 1995).

Schön, D. A. (1987). Educating the reflective practitioner: Toward a new design for teaching and learning in the professions. San Francisco: Jossey-Bass.

Soobik, M. (2014). Teaching methods influencing the sustainability of the teaching process in technology education in general education schools. Journal of Teacher Education for Sustainability, 16(1), 89-101.

Tate, S., \& Sills, M. (Eds.) (2004). The development of critical reflection in the health professions. London: Higher Education Authority.

Tomlinson, P. (1999a). Conscious reflection and implicit learning in teacher preparation, Part 1: Recent light on an old issue. Oxford Review of Education, 25(3), 405-424.

Tomlinson, P. (1999b). Conscious reflection and implicit learning in teacher preparation, Part II: Implications for a balanced approach. Oxford Review of Education, 25(4), 533-544.

Yoo, Julia, H. (2016). The Effect of professional development on teacher efficacy and teachers' self-analysis of their efficacy change. Journal of Teacher Education for Sustainability, 18(1), 84-94.

Zahavi, D. (2004d). Time and consciousness in the Bernau manuscripts. Husserl Studies 20(2), 99-118.

Zeichner, K., \& Liston, D. (1996). Reflective teaching: An introduction. Mahwah, NJ: Lawrence Erlbaum.

Correspondence concerning this paper should be addressed to Abdulwali Hussien Aldahmash, PhD, King Saud University, P. O. Box 2458, Riyadh 11451, Kingdom of Saudi Arabia. Emails: wadialsail@gmail.com, aaldahmash@ksu.edu.sa 